\title{
NSF Workshop Report: Discovering General Principles of Nervous System Organization by Comparing Brain Maps across Species
}

\author{
Georg F. Striedter ${ }^{\mathrm{a}} \quad$ T. Grant Belgard ${ }^{\mathrm{b}}$ Chun-Chun Chen ${ }^{\mathrm{c}}$ Fred P. Davis $^{\mathrm{d}}$ \\ Barbara L. Finlaye Onur Güntürkün ${ }^{f}$ Melina E. Hale ${ }^{g}$ Julie A. Harris ${ }^{\text {h }}$ Erin E. Hecht ${ }^{i}$ \\ Patrick R. Hof ${ }^{j}$ Hans A. Hofmann ${ }^{k}$ Linda Z. Holland' Andrew N. Iwaniuk ${ }^{m}$ Erich D. Jarvis ${ }^{c}$ \\ Harvey J. Karten ${ }^{\text {n }}$ Paul S. Katz ${ }^{\circ}$ William B. Kristan ${ }^{p}$ Eduardo R. Macagno ${ }^{q}$ Partha P. Mitra ${ }^{r}$ \\ Leonid L. Moroz ${ }^{s}$ Todd M. Preuss ${ }^{t}$ Clifton W. Ragsdale ${ }^{\mathrm{u}}$ Chet C. Sherwood $^{\mathrm{v}}$ \\ Charles F. Stevens $^{w}$ Maik C. Stüttgen ${ }^{f}$ Tadaharu Tsumoto ${ }^{\mathrm{x}}$ Walter Wilczynskio $^{\circ}$

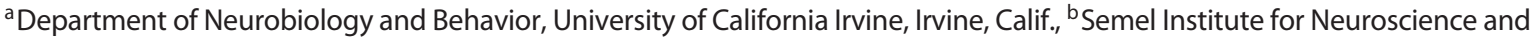 \\ Human Behavior, University of California Los Angeles, Los Angeles, Calif., 'Department of Neurobiology, Duke University, Durham, \\ N.C., d Janelia Farm Research Campus, Howard Hughes Medical Institute, Ashburn, Va., e Department of Psychology, Cornell University, \\ Ithaca, N.Y., USA; f Department of Psychology, Ruhr University Bochum, Bochum, Germany; ${ }^{9}$ Department of Organismal Biology and \\ Anatomy, University of Chicago, Chicago, III., h Allen Institute for Brain Science, Seattle, Wash., 'Department of Psychology, Georgia \\ State University, Atlanta, Ga., jFishberg Department of Neuroscience and Friedman Brain Institute, Icahn School of Medicine at Mount \\ Sinai, New York, N.Y., kDepartment of Cell and Molecular Biology, University of Texas at Austin, Austin, Tex., 'Scripps Institution of \\ Oceanography, University of California San Diego, San Diego, Calif., USA; mDepartment of Neuroscience, University of Lethbridge, \\ Lethbridge, Alta., Canada; ${ }^{n}$ Department of Neurosciences, University of California San Diego, San Diego, Calif., ${ }^{\circ}$ Neuroscience \\ Institute, Georgia State University, Atlanta, Ga., Sections of ${ }^{\mathrm{P}}$ Neurobiology and ${ }^{\mathrm{C}}$ Cell and Developmental Biology, Division of \\ Biological Sciences, University of California San Diego, San Diego, Calif., ' Cold Spring Harbor Laboratory, Cold Spring Harbor, N.Y., \\ sDepartment of Neuroscience and The Whitney Laboratory for Marine Bioscience, University of Florida, St. Augustine, Fla., \\ 'Division of Neuropharmacology and Neurologic Diseases, Yerkes National Primate Research Center, Emory University, Atlanta, Ga., \\ uDepartment of Neurobiology, University of Chicago, Chicago, III., ' Department of Anthropology, The George Washington University,

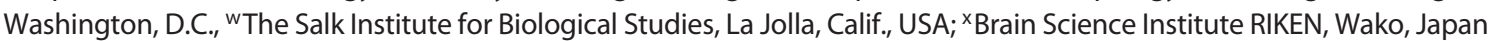

\begin{abstract}
Efforts to understand nervous system structure and function have received new impetus from the federal Brain Research through Advancing Innovative Neurotechnologies (BRAIN) Initiative. Comparative analyses can contribute to this effort by leading to the discovery of general principles of neural circuit design, information processing, and gene-structurefunction relationships that are not apparent from studies on single species. We here propose to extend the comparative approach to nervous system 'maps' comprising molecular,
\end{abstract}

anatomical, and physiological data. This research will identify which neural features are likely to generalize across species, and which are unlikely to be broadly conserved. It will also suggest causal relationships between genes, development, adult anatomy, physiology, and, ultimately, behavior. These causal hypotheses can then be tested experimentally. Finally, insights from comparative research can inspire and

This article is simultaneously published in the Journal of Comparative Neurology (DOI 10.1002/cne.23568).

\section{KARGER}

E-Mail karger@karger.com www.karger.com/bbe (c) 2014 John Wiley \& Sons, Inc. and S. Karger AG, Basel 0006-8977/14/0831-0001\$39.50/0
Georg F. Striedter

Department of Neurobiology and Behavior

Center for the Neurobiology of Learning and Memory, University of California Irvine 2205 McGaugh Hall, Irvine, CA 92697-4550 (USA)

E-Mail georg.striedter@gmail.com 
guide technological development. To promote this research agenda, we recommend that teams of investigators coalesce around specific research questions and select a set of 'reference species' to anchor their comparative analyses. These reference species should be chosen not just for practical advantages, but also with regard for their phylogenetic position, behavioral repertoire, well-annotated genome, or other strategic reasons. We envision that the nervous systems of these reference species will be mapped in more detail than those of other species. The collected data may range from the molecular to the behavioral, depending on the research question. To integrate across levels of analysis and across species, standards for data collection, annotation, archiving, and distribution must be developed and respected. To that end, it will help to form networks or consortia of researchers and centers for science, technology, and education that focus on organized data collection, distribution, and training. These activities could be supported, at least in part, through existing mechanisms at NSF, NIH, and other agencies. It will also be important to develop new integrated software and database systems for cross-species data analyses. Multidisciplinary efforts to develop such analytical tools should be supported financially. Finally, training opportunities should be created to stimulate multidisciplinary, integrative research into brain structure, function, and evolution.

(C) 2014 S. Karger AG, Basel

\section{Introduction}

A major focus of the Brain Research through Advancing Innovative Neurotechnologies (BRAIN) Initiative, announced by President Obama on April 2, 2013, is to produce 'dynamic pictures of the brain that show how individual brain cells and complex circuits interact at the speed of thought' [quoted in: BRAIN Working Group, 2013, p. 4]. The ultimate aim of this research effort, as well as others like it around the world, is to understand the functioning of human brains. However, much of the research will necessarily focus on nonhuman species, in which novel technologies can be developed and applied more efficiently, and research can be conducted at more reductionist levels. For example, the Japanese brain mapping initiative will focus on marmoset monkeys (Callithrix jacchus), a species that can be manipulated genetically [Sakai et al., 2009], yet has a neocortex that is more similar to human neocortex than that of other common laboratory species. Other brain mapping projects will include research on species with smaller nervous systems, such as nematodes (Caenorhabditis elegans), fruit flies (Drosophila melanogaster), zebra fish (Danio rerio), and a few other species, because those nervous systems are easier to map in their entirety than the brains of larger animals. Although the various brain mapping projects will include a variety of nonhuman species, the major discoveries coming out of this research are expected to generalize across species to humans.
The use of traditional laboratory model species has been extremely successful, both in neuroscience and more generally [Krebs, 2005], but comparative neurobiology of non-model species can provide critical additional insights into fundamental principles of nervous system organization. For example, more than 100 years ago, Brodmann [1909] compared the cerebral cortex of many different mammals and discovered that, although some cortical areas contain more or less than 6 layers, a division into 6 layers best captures the complex pattern of similarities and differences in cortical lamination seen across species. Similarly, comparisons of central pattern generators across a wide variety of species, both invertebrate and vertebrate, revealed important principles of how groups of neurons generate rhythmic patterns of activity through the interaction of membrane properties and synaptic connectivity [Marder and Bucher, 2001]. In both examples, general principles emerged from a comparative analysis of both similarities and differences across species. A third instructive illustration of the fruits of a comparative approach is the discovery that similar computations involving learning and memory may be performed by very different neural networks even in closely related taxa, notably octopus and cuttlefish [Shomrat et al., 2011; Hochner, 2013].

Given the broad benefits of the comparative approach, it is important to contemplate how one might best extend a comparative perspective to brain mapping initiatives. To answer this question, the au- thors of this essay gathered for an NSFsponsored workshop at the Janelia Farm Research Campus of the Howard Hughes Medical Institute on October 23-25, 2013. After several introductory presentations, the participants formed six small groups, each tackling a different central question but also thinking about overarching issues. The following day, each group presented their main recommendations, and then all participants engaged in an extensive discussion. Also participating were representatives from the NSF, the NIH, and the White House Office of Science and Technology. After lively debate, several core areas of agreement emerged. A white paper summarizing these debates and the emerging consensus, as well as statements from individual participants and video footage, can be found at understandingthebrain. org (see also brainsacrossphylogeny.org). The present document is a more formal report on the group discussions and recommendations.

In brief, we agreed that comparative studies, including both broad comparisons across widely divergent organisms and targeted studies of more closely related species, can provide important information about fundamental principles of nervous system organization, including principles of variation and innovation. We stress that data should be collected to address specific research questions that can be answered uniquely through comparative analyses. Such a comparative approach would benefit from identifying one or more 'reference species' as initial targets for thorough map- 
ping. These reference species may be compared to one another, but may also serve as anchors for comparative analyses of other, closely related species. Collectively, these comparisons are expected to reveal both species similarities and differences, thus disclosing both highly conserved features and variation. We also recommend that all data be gathered in standardized ways that facilitate comparative analyses. Finally, we encourage funding agencies to support training in comparative research and the development of new technologies and methodologies for comparative data collection and analysis. In the following sections, we expand on these core recommendations.

\section{Goals of the Comparative Approach to Brain Mapping}

Comparative neuroscience allows the evolutionary history of neural traits to be reconstructed. By analyzing the distribution of those neural traits across multiple species, whose phylogenetic relationships have already been clarified, neuroscientists can reconstruct when the traits first evolved, identify which species inherited the traits from a common ancestor, and establish in which lineages the traits were modified or lost. Although such character phylogeny reconstructions may be amended as more species are sampled and phylogenies revised, the underlying methodology is well established [Northcutt, 1984; Nieuwenhuys, 1994]. As brain maps become more detailed and cover an increasing number of species, it will be possible to reconstruct the history of how nervous systems evolved in substantial detail [Bierman et al., 2009]. Such research is important, because it transforms an otherwise chaotic pattern of neural similarities and differences across extant species into a historical sequence of how those nervous systems evolved. This historical context, in turn, provides the basis for extracting general principles of conservation and variation in neural structure and function at all levels of analysis. For example, comparative analyses have shown that some brain regions and neuronal pathways are surprisingly conserved across all vertebrates [Karten and Shimizu, 1989; Shanahan et al., 2013] and, perhaps, across most animals [Farries, 2013; Strausfeld and Hirth, 2013a, b]. Similarly, many of the genes involved in pat- terning the nervous system during early development are far more conserved across phylogeny than researchers had expected [Pani et al., 2012; Holland et al., 2013].

These discoveries of unexpected 'deep' conservation lurking below more superficial species differences are important because they promote the unification of our knowledge about all nervous systems. In addition, they help us predict which features are likely to exist in species not yet examined. For example, features that are shared across leeches, insects, teleost fishes, birds, mice, and marmosets are likely to exist in humans as well. Conversely, features that are only found in some mouse strains, but not others, are less likely to be present in us. Thus, comparative research can help predict which neurobiological principles can be extrapolated to humans and, thus, serve as a basis for therapeutic interventions. By contrast, the model species approach, applied in isolation, has led to rather limited success in the development of human therapies [van der Worp et al., 2010].

Although the discovery of unexpected conservation is both fascinating and useful, the analysis of species differences can also be invaluable. Closest to home, careful comparisons between human and nonhuman primate brains can show what makes our human brains unique [Preuss, 2012; Sherwood et al., 2012; Fjell et al., 2013; Finlay and Workman, 2013; Passingham and Wise, 2013], at least among primates [Petkov and Jarvis, 2012]. In addition, variation in neural traits can generate novel hypotheses about the mechanisms underlying those traits. For example, one may ask whether a species difference in brain anatomy or physiology correlates with a species difference in gene expression, either in the adult nervous system or its developmental precursors. Such a correlation would suggest a causal link between the genes and the anatomical or physiological features, which can then be tested experimentally. Similarly, researchers may ask whether a species difference in some behavioral trait or cognitive capacity correlates with specific molecular, neuroanatomical, or neurophysiological features. Such a comparative approach revealed, for example, that species differences in associative learning among three species of sea hares, including the well-known Aplysia californica, correlate well with differences in neuromodulation [Hoover et al., 2006]. This comparative finding helps to link experimental studies in Aplysia to general proposals about the mechanisms underlying learning and memory. Comparative studies have also shown that human brains exhibit dendritic specializations and molecular expression patterns that may be unique to our species and are likely to foster synaptic plasticity [Somel et al., 2009; Konopka et al., 2012; Bianchi et al., 2013].

Comparative research that focuses on variation, rather than conservation, can also lead to the discovery of general principles. Consider, for example, a behavior or cognitive capacity that has evolved repeatedly in diverse species, and that in each instance is correlated with similar neural circuits or physiological mechanisms. Such convergent similarities suggest general principles relating structure to function. For example, some birds and some great apes have independently evolved a capacity for tool use and mirror self-recognition, and both groups of species exhibit similar, though independently evolved, neural circuits controlling those behaviors [Prior et al., 2008; Striedter, 2013]. Similarly, the neural circuits mediating vocal learning in songbirds and parrots bear some similarity to human language circuits [Petkov and Jarvis, 2012], even though they are most likely not homologous. Such independently evolved neurobehavioral similarities strongly suggest the existence of computational constraints that limit the possible neural mechanisms capable of generating the respective forms of cognition. Analogous studies of variation in brain development and adult nervous system organization can reveal general principles of evolution and development [Finlay and Darlington, 1995; Charvet et al., 2011]. Such insights could not be gleaned without comparative analyses.

Scaling rules have long played a major role in our understanding of organismal physiology [Schmidt-Nielsen, 1984; Savage et al., 2007; Levy and Heald, 2012], and they are also major principles in comparative neurobiology. Indeed, numerous neural traits vary predictably with absolute brain size. For example, brain region proportions, neuron numbers, and average connectivity change predictably with absolute brain size in diverse lineages [Striedter, 2005; Yopak et al., 2010]. Although the specific scaling rules may vary among lineages [Herculano-Houzel et al., 2007, 2011; Lewitus et al., 2012; van der Woude et al., 2013], the rules themselves are nonetheless key components of nervous system design. 
Moreover, the malleability of evolutionary scaling rules itself raises an important question: what mechanisms generate the scaling rules? Increases in brain size are accompanied, at least in mammals, by increases in neurogenesis duration, which has predictable but nonlinear consequences for the size of individual brain areas [Finlay and Darlington, 1995]. However, the mechanisms that regulate neurogenesis duration remain largely unknown. Moreover, the functional consequences of most neuronal scaling rules have not been thoroughly explored [Karbowski, 2007; Bakken and Stevens, 2012]. As comparative brain mapping flourishes, more progress on these fronts is expected.

In summary, comparative neuroscience is a rich discipline capable of answering a broad array of questions that are critically important for understanding nervous system design. Although it might be tempting to collect comparative data before one worries about which questions those data may answer, we recommend that researchers identify key questions first and then select the species whose brains they want to map in light of those questions. Of course, in the long run, emerging data sets can also be mined to answer new, previously neglected questions.

\section{Constructing Comparative Brain Maps}

Nervous system 'maps' may contain multiple types of data at multiple spatial and temporal scales. They may cover entire brains or smaller subsystems. Anatomical brain maps may be macroscopic, in the sense that they map major brain divisions and cell groups. Particularly important are mesoscopic maps using light microscopy [Bohland et al., 2009], which focus on an intermediate scale of nervous system organization, corresponding to relatively restricted collections of specific cell types, including glia as well as neurons. Anatomical mapping at the mesoscopic scale has two important components: histological maps providing the spatial distribution of different cell types and circuit connectivity maps determined with neuroanatomical tracers, including classical tracer substances as well as neurotropic viruses. We suspect that these mesoscopic maps will be most useful for most comparative analyses, at least initially. However, some species with very small nervous systems, such as $C$. elegans and diverse other invertebrates [Lacalli and Kelly, 2003], as well as small portions of vertebrate nervous systems [Helmstaedter et al., 2013], are amenable to electron-microscopic reconstructions of all neuronal processes and their synaptic connections. Of course, the level of detail at which a brain is mapped should be determined not only by practical concerns, but also by the questions that are to be addressed. For example, if the questions concern development, then maps must be constructed not just for adults, but also for strategically selected embryonic and juvenile stages.

Molecular brain maps likewise come in several varieties. Gene expression patterns can be mapped in whole brains, if they are small, or in tissue sections, using nucleic acid probes. At a more detailed level, unbiased gene expression profiles can be created for single cells using RNA-Seq or other cutting-edge techniques [Puthanveettil et al., 2013; Serrano-Saiz et al., 2013]. The technology for mapping proteins across species is more limited, mainly because antibodies that work well in some species often do not work in others, but technical advances in imaging mass spectroscopy [Nicklay et al., 2013] promise to overcome those challenges and also make it possible to map the distribution of lipids and other molecules for which antibodies cannot be used. Another, more general problem is that the molecular data must be spatially aligned and integrated with the histological and circuit data. When this is done, both sets of data become more valuable. In particular, gene expression patterns can help define cortical areas, cell groups, and specific cell types [Jarvis et al., 2013]. Integrating both molecular and anatomical data is especially helpful in developmental studies, where regions or cells must be tracked across successive stages of development [Chen et al., 2013]. Fate mapping or lineage analyses will likely be needed to complement such stage-by-stage developmental analyses.

Methods for mapping neural activity tend to vary in their spatial and temporal resolutions. Functional magnetic resonance imaging and positron emission tomography, for example, have relatively low spatial and temporal resolution, but are useful for comparing large-scale patterns of neural activity across primate brains [Rilling et al., 2007; Mantini et al., 2013; Wey et al., 2013]. Single cell recordings, using microelectrodes, optical imaging, or immediate early gene expression techniques, can be used to map neural activity at the mesoscopic scale. The activity data must then be correlated with the corresponding anatomical data and behavior [Alivisatos et al., 2012; Jarvis et al., 2013]. A major challenge for the construction of neural activity maps is to select appropriate conditions or behaviors. In some cases, it may be best to record 'resting state' activity, but defining this state can be problematic [Stark and Squire, 2001]. Furthermore, mapping activity during behavior will be more relevant to answering questions about the evolution of specific behaviors or cognitive capacities.

This raises an important point: if one goal of the research is to understand the neural bases of behavior in diverse species, then the behaviors of interest must be examined thoroughly. Indeed, comparative behavioral studies can reveal important general principles in their own right. It is now clear, for example, that both associative and non-associative forms of learning, such as habituation and classical conditioning, are very broadly conserved across both vertebrate and invertebrate species [Macphail, 1982; Giurfa and Sandoz, 2012; Sakura and Mori, 2013]. Just as Dobzhanski [1973] once observed that 'nothing in biology makes sense except in the light of evolution', so others have proposed that 'nothing in neuroscience makes sense except in the light of behavior' [BRAIN Working Group, 2013]. From a comparative perspective, both statements are equally true.

A general challenge for all brain mapping initiatives is to integrate molecular, anatomical, physiological, and behavioral data with one another. To facilitate this integration, it is important for researchers to agree on a spatial coordinate system in which the data can be represented. Developmental data require, in addition, a welldefined staging system [Workman et al., 2013]. Such spatial and temporal coordinate systems have been developed for several different species, but applying them to species that have not yet been studied thoroughly can be difficult. For example, closely related species may progress through similar developmental stages at different absolute rates [Striedter and Charvet, 2008], and homologous brain areas may be located at different spatial locations in different species [Nieuwenhuys, 2009].

Another major challenge for comparative brain mapping projects is to perform quantitative comparisons. Even the appar- 
ently simple task of comparing the size of brain regions across species is fraught with challenges, as a region's size can be compared in absolute terms, relative to the entire brain, relative to the remaining brain, relative to a specific reference structure, or relative to expectations based on scaling rules. Different measures may yield different results when they are correlated against behavioral or cognitive traits [Lefebvre, 2012], but researchers rarely agree on which measures are best. Conducting quantitative comparisons of connectomes, gene expression patterns, or neural activity maps is likely to be at least as challenging and will likely require some novel analytical approaches [Belgard et al., 2013; Belgard and Montiel, 2013]. This is an area where research on new computational and bioinformatic approaches to neural data would be invaluable.

These observations raise a general question: how can homologous features, ranging from cell types to behaviors, be identified in different species? Comparative neurobiologists have long debated this question [Striedter and Northcutt, 1991], but comparative brain mapping initiatives promise to clarify at least some of these debates. For example, similar gene expression patterns may help to recognize homologous cell types or brain regions [Dugas-Ford et al., 2012; Vopalensky et al., 2012; Belgard et al., 2013; Jarvis et al., 2013; Medina et al., 2013], and so might similarities in physiological activity and functional role. It should be noted, however, that it is possible for similar cell types to be located in nonhomologous brain regions, for dissimilar neural networks to perform similar functions, and for homologous adult structures to develop from disparate developmental precursors [Striedter and Northcutt, 1991]. Indeed, such instances of non-correspondence among different levels of organization may provide vital clues to how complex systems operate and evolve.

\section{Selecting Reference Species}

The most basic goals of a comparative approach to brain mapping are to identify broadly conserved features of nervous system structure and function, to identify variation in those features that characterize particular taxonomic groups, and then to understand how variation in one domain (e.g., the expression of some gene network) relates to variation in another (e.g., a devel- opmental trajectory or pattern of behavior). Ultimately, those goals can only be satisfied by both a broad survey of organisms and a deep analysis of closely related species with clearly understood differences. In order to advance these goals, we recommend a strategic effort to target carefully selected species from phylogenetically widely spaced vertebrate and invertebrate groups for thorough mapping in several domains, especially for generating connectomes and nervous system transcriptomes. These 'reference species' would then serve two purposes: as substrates for broad comparisons across all animals to identify nervous system fundamentals and as anchors for more fine-grained analyses within their particular taxon to assess the meaning of variation in whole brains and functional subsystems.

Some of the reference species will be the traditional 'model species' of neuroscience (notably humans, macaques, rats, mice, zebra fish, fruit flies, and the roundworm C. elegans), because they offer numerous practical advantages, as well as existing research communities and large reservoirs of existing data. For example, brain maps of laboratory mice may serve as references for comparisons to nonmammalian brains, other rodents, and other mouse species or strains. Similarly, human brain maps may serve as references for broad comparative analyses, as well as for fine-grained comparisons with chimpanzees and other apes.

However, many reference species are likely to come from outside the ranks of the traditional model species. To select these other reference species, researchers may consider various criteria. In some cases, phylogenetic position may be paramount. For example, acorn worms or lancelets may be useful reference species for comparisons that span both vertebrate and invertebrate nervous systems, because of their phylogenetic position near the origin of vertebrates [Cameron et al., 2000]. In other cases, it may be more important that the genome of the species is sequenced and well annotated, that its nervous system is small or relatively easy to map, that the species is easy to maintain and breed, that key aspects of its biology have already been studied in detail, that a substantial scientific community is already using the species in its research, or that the questions that can be answered using the species are particularly important. Although a consensus may emerge on the criteria for selecting a reference species, decisions about how to weight the various criteria must be made on a case-by-case basis.

In the long run, we envision the phylogenetic tree of animals becoming populated with an ever-increasing number of species whose nervous systems have been mapped to varying extents, with especially detailed analyses of the selected reference species. As those brain maps proliferate, ever more research questions can be addressed through ever broader or more detailed comparative analyses. This vision has an analogy in the history of animal genomics. Initially, a few key species were studied (worm, fly, mouse, and human). Now many different species have been sequenced, with their annotations depending crucially on the assembly of first- and second-generation animal genomes. We envision a similar benefit to brain mapping research in focusing initially on a few reference species, which then provide a crucial framework for studying a greater range of animal nervous systems.

\section{Specific Recommendations}

\section{Selecting Reference Species}

As noted earlier, we recommend a comparative approach that addresses both conserved features and variation, and is anchored in a set of strategically selected reference species. Comparisons need not be limited to the selected reference species, but may use them as useful bases for comparison. For example, a brain map in one reference species may be used to delineate a specific neural subsystem, which can then be mapped selectively in other species. Conversely, isolated bits of data from multiple species about which not much is known can be compared more easily to one another if they are first compared to the comprehensive map in a strategically selected reference species. Thus, reference species provide an anchor for comparative analyses. They serve not as models for some other species, but as a basis for comparisons that may reveal both similarities and differences.

\section{Collaborative Research Teams}

Because the task of mapping the nervous systems of multiple species is usually beyond the capabilities of single laboratories, we recommend that researchers organize themselves, as much as possible, into collaborative teams around specific re- 
search questions and around groups of species through which those questions can be answered effectively. These teams should collectively decide which species should be targeted and select the relevant reference species. Funding agencies may support such efforts through awards to establish organized research networks and consortia. In the long run, significant support should come through collaborative research grants.

\section{Data Standardization}

Collaborative research teams should also develop standards for data collection and storage. For example, the data should be stored in standardized file formats so that it can be analyzed with common visualization software. In addition, section planes and scale information should be standardized as much as possible. One may even want to standardize tissue processing techniques and imaging parameters, at least when large-scale multispecies comparisons are planned. Finally, data annotation should be performed according to agreed-upon procedures. We support a bottom-up process in which investigators working with related techniques coalesce around emerging standards, but we recommend that these standardization efforts be coordinated with those of other groups, such as the International Neuroinformatics Coordinating Facility (INCF.org). The major funding agencies or other organizations may also promote data standardization through data sharing plans in research proposals.

\section{Technical Support}

Data collection on the envisioned scale requires expensive instruments and skilled labor. Anatomical mapping at the mesoscopic scale is most efficiently performed with modern slide scanners, rather than traditional microscopes. Mapping at microscopic scales requires even more expensive equipment and considerable expertise. One way to minimize these technical chal- lenges is to create research centers that have the requisite equipment and expertise. Individual researchers could utilize these centers to collect their data at reduced costs and, we hope, according to the standards of the research center and the broader community. In addition, some technologies, especially analysis software, could be developed at a few central locations and disseminated widely to the research community. This technical support could be funded by multiple agencies.

\section{Data Sharing and Analysis}

Comparative brain mapping data should be publicly accessible over the internet so that they can be analyzed by scientists around the world. To facilitate analyses, new tools will need to be developed. Most important will be tools that enable comparisons of data from brains that are at least superficially dissimilar and harbor unresolved homologies. To that end, collaborations with experts in multivariate statistics and phylogenetic systematics may prove especially fruitful. Funding agencies can support such interdisciplinary efforts through programs such as the NSF call for 'Advances in Biological Informatics'.

\section{Cross-Training}

Individuals in one discipline or working on one group of organisms often lack the expertise to appreciate the work performed in other disciplines or other species. However, major breakthroughs in comparative neuroscience will almost certainly require researchers who can cross disciplinary boundaries and integrate data from diverse species. Therefore, scientists should be encouraged to organize workshops, courses, and meetings that bring together researchers with diverse backgrounds, ranging from evolutionary biology and genomics to statistics and computational biology. Especially important is cross-disciplinary training for graduate students and postdoctoral researchers.

\section{Conclusion}

Our 2-day workshop to discuss the future of comparative brain mapping produced lively debates but also more agreement than one might have expected. A strong consensus formed around the view that data should be collected in the pursuit of specific questions, not simply because the technology for collecting the data now exists. In addition, workshop participants resonated with the concept of a reference species, which differs from the concept of a model species in explicitly testing for species differences and spanning phylogenetic diversity in a principled, meaningful way. We discussed which species might make good reference species for some types of comparisons, but in the end we felt that these decisions are best left to self-organizing groups of researchers rather than our working group. The aim of this article is to promote the formation of such collaborative teams and help them on their path. We look forward to an ever-expanding universe of comparative neural data that will yield important and unexpected discoveries.

\section{Acknowledgments}

This workshop was supported by NSF grant IOS-1352894. We thank James Deshler and Diane Witt at the NSF for providing its impetus. We also thank Janelia Farm and its director, Gerald Rubin, for generously hosting the workshop. Much appreciated was the help of Janine Stevens at Janelia Farm and Julia Pisias at the University of California Irvine, who expertly handled the workshop logistics. Thanks also to Sara Bradley, who set up the website where other documents and videos associated with this workshop may be found: http://understandingthebrain. org/.

\section{References}

Alivisatos AP, Chun M, Church GM, Greenspan RJ, Roukes ML, Yuste R (2012): The brain activity project and the challenge of functional connectomics. Neuron 74:970-974.

Bakken TE, Stevens CF (2012): Visual system scaling in teleost fish. J Comp Neurol 520:142-153.

Belgard TG, Montiel JF (2013): Things change: how comparative transcriptomics suggest the pallium has evolved at multiple levels of organization. Brain Behav Evol 82:150-152.
Belgard TG, Montiel JF, Wang WZ, GarcíaMoreno F, Margulies EH, Ponting CP, Molnár Z (2013): Adult pallium transcriptomes surprise in not reflecting predicted homologies across diverse chicken and mouse pallial sectors. Proc Natl Acad Sci USA 110:1315013155. 
Bianchi S, Stimpson CD, Bauernfeind AL, Schapiro SJ, Baze WB, McArthur MJ, Bronson E, Hopkins WD, Semendeferi K, Jacobs B, Hof PR, Sherwood CC (2013): Dendritic morphology of pyramidal neurons in the chimpanzee neocortex: regional specializations and comparisons to humans. Cereb Cortex 23:2429-2436.

Bierman HS, Zottoli SJ, Hale ME (2009): Evolution of the Mauthner axon cap. Brain Behav Evol 73:174-187.

Bohland JW, Wu C, Barbas H, Bokil H, Bota M, Breiter HC, Cline HT, Doyle JC, Freed PJ, Greenspan RJ, Haber SN, Hawrylycz M, Herera DG, Hilgetag CC, Huang ZJ, Jones A, Jones EG, Karten HJ, Kleinfeld D, Kötter R, Lester HA, Lin JM, Mensh BD, Mikula S, Panksepp J, Price JL, Safdieh J, Saper CB, Schiff ND, Schmahmann JD, Stillman BW, Svoboda K, Swanson LW, Toga AW, Van Essen DC, Watson JD, Mitra PP (2009): A proposal for a coordinated effort for the determination of a brainwide neuroanatomical connectivity in model organisms at a mesoscopic scale. PLoS Comput Biol 5:e1000334.

BRAIN Working Group (2013): Interim report. http://www.nih.gov/science/brain/ 09162013-Interim\%20Report_Final\%20 Composite.pdf.

Brodmann K (1909): Vergleichende Lokalisationslehre der Grosshirnrinde. Leipzig, Barth; translated by L. Garey (2007): Brodmann's Localisation in the Cerebral Cortex. London, Imperial College Press.

Cameron CB, Garey JR, Swalla BJ (2000): Evolution of the chordate body plan: new insights from phylogenetic analyses of deuterostome phyla. Proc Natl Acad Sci USA 97:4469-4474.

-Charvet CJ, Striedter GF, Finlay BL (2011): Evodevo and brain scaling: candidate developmental mechanisms for variation and constancy in vertebrate brain evolution. Brain Behav Evol 78:248-257.

-Chen C-C, Winkler CM, Pfenning AR, Jarvis ED (2013): Molecular profiling of the developing avian telencephalon: regional timing and brain subdivision continuities. J Comp Neurol 521:3666-3701.

Dobzhansky T (1973): Nothing in biology makes sense except in the light of evolution. Am Biol Teacher v.35; reprinted in Zetterberg JP (ed): Evolution versus Creationism. Phoenix, ORYX Press, http://www.2think.org/ dobzhansky.shtml.

> Dugas-Ford J, Rowell JJ, Ragsdale CW (2012): Cell-type homologies and the origins of the neocortex. Proc Natl Acad Sci USA 109: 16974-16979.

Farries MA (2013): How 'basal' are the basal ganglia? Brain Behav Evol 82:211-214.

Finlay BL, Darlington RB (1995): Linked regularities in the development and evolution of mammalian brains. Science 268:1578-1584.

Finlay BL, Workman AJ (2013): Human exceptionalism. Trends Cogn Sci 17:199-201.
Fjell AM, Westlye LT, Amlien I, Tamnes CK, Grydeland H, Engvig A, Espeseth T, Reinvang I, Lundervold AJ, Lundervold A, Walhovd KB (2013): High-expanding cortical regions in human development and evolution are related to higher intellectual abilities. Cereb Cortex, DOI: 10.1093/cercor/ bht201.

Giurfa M, Sandoz JC (2012): Invertebrate learning and memory: fifty years of olfactory conditioning of the proboscis extension response in honeybees. Learn Mem 19:54-66.

Helmstaedter M, Briggman KL, Turaga SC, Jain V, Seung S, Denk W (2013): Connectomic reconstruction of the inner plexiform layer in the mouse retina. Nature 500:168-174.

Herculano-Houzel S, Collins CE, Wong P, Kaas JH (2007): Cellular scaling rules for primate brains. Proc Natl Acad Sci USA 104:3562-3567.

Herculano-Houzel S, Ribeiro P, Campos L, Valotta da Silva A, Torres LB, Catania KC, Kaas JH (2011): Updated neuronal scaling rules for the brains of Glires (rodents/lagomorphs). Brain Behav Evol 78:302-314.

Hochner B (2013): How nervous systems evolve in relation to their embodiment: what we can learn from octopuses and other molluscs. Brain Behav Evol 82:19-30.

-Holland LZ, Carvalho JE, Escriva H, Laudet V, Schubert M, Shimeld SM, Yu J-K (2013): Evolution of bilaterian central nervous systems: a single origin? EvoDevo 4:27.

$>$ Hoover BA, Nguyen H, Thompson L, Wright WG (2006): Associative memory in three aplysiids: correlation with heterosynaptic modulation. Learn Mem 13:820-826.

Jarvis ED, Yu J, Rivas MV, Horita H, Feenders G, Whitney O, Jarvis SC, Jarvis ER, Kubikova L, Puck AEP, Siang-Bakshi C, Martin S, McElroy $M$, Hara E, Howard J, Pfenning A, Mouritsen H, Chen C-C, Wada K (2013): Global view of the functional molecular organization of the avian cerebrum: mirror images and functional columns. J Comp Neurol 16:36143665.

Karbowski J (2007): Global and regional brain metabolic scaling and its functional consequences. BMC Biol 5:18.

Karten HJ, Shimizu T (1989): The origins of neocortex: connections and lamination as distinct events in evolution. J Cogn Neurosci 1: 291-301.

Konopka G, Friedrich T, Davis-Turak J, Winden K, Oldham MC, Gao F, Chen L, Wang GZ, Luo R, Preuss TM, Geshwind DH (2012): Human-specific transcriptional networks in the brain. Neuron 75:601-617.

Krebs HA (2005): The August Krogh principle: 'for many problems there is an animal on which it can be most conveniently studied'. J Exp Zool 194:221-226.

Lacalli TC, Kelly SJ (2003): Ventral neurons in the anterior nerve cord of amphioxus larvae. I. An inventory of cell types and synaptic patterns. J Morphol 257:190-211.

Lefebvre L (2012): Primate encephalization. Prog Brain Res 195:393-412.
Levy DL, Heald R (2012): Mechanisms of intracellular scaling. Annu Rev Cell Dev Biol 28:113135 .

Lewitus E, Hof PR, Sherwood CC (2012): Phylogenetic comparison of neuron and glia densities in the primary visual cortex and hippocampus of carnivores and primates. Evolution 66:2551-2563.

Macphail EM (1982): Brain and Intelligence in Vertebrates. Oxford, Clarendon Press.

Mantini D, Corbetta M, Romani GL, Orban GA, Vanduffel W (2013): Evolutionarily novel functional networks in the human brain? J Neurosci 33:3259-3275.

Marder W, Bucher D (2001): Central pattern generators and the control of rhythmic movements. Curr Biol 11:R986-R996.

Medina L, Abellán A, Desfilis E (2013): A neverending search for the evolutionary origin of the neocortex: rethinking the homology concept. Brain Behav Evol 81:150-153.

Nicklay JJ, Harris GA, Schey KL, Caprioli RM (2013): MALDI imaging and in situ identification of integral membrane proteins from rat brain tissue sections. Anal Chem 85:71917196.

Nieuwenhuys R (1994): Comparative neuroanatomy: place, principles, practice and programme. Eur J Morphol 32:142-155.

Nieuwenhuys R (2009): The forebrain of actinopterygians revisited. Brain Behav Evol 73:229252.

Northcutt RG (1984): Evolution of the vertebrate central nervous system: patterns and processes. Am Zool 24:701-716.

Pani AM, Mullarkey EE, Aronowicz J, Assimacopoulos S, Grove EA, Lowe CJ (2012): Ancient deuterostome origins of vertebrate brain signalling centres. Nature 283:989-294.

Passingham RE, Wise SP (2013): The Neurobiology of the Prefrontal Cortex: Anatomy, Evolution, and the Origin of Insight. Oxford, Oxford University Press.

Petkov CI, Jarvis ED (2012): Birds, primates, and spoken language origins: behavioral phenotypes and neurobiological substrates. Front Evol Neurosci 4:12.

Preuss TM (2012): Human brain evolution: from gene discovery to phenotypic discovery. Proc Natl Acad Sci USA 109(suppl 1):1070910716.

Prior H, Schwarz A, Güntürkün O (2008): Mirror-induced behavior in the magpie (Pica pica): evidence of self-recognition. PLoS Biol 6:e202.

Puthanveettil SV, Antonov I, Kalachikov S, Rajasethupathy P, Choi Y-B, Kohn AB, Citarella M, Yu F, Karl KA, Kinet M, Morozova I, Russo JJ, Ju J, Moroz LL, Kandel ER (2013): A strategy to capture and characterize the synaptic transcriptome. Proc Natl Acad Sci USA 110:7464-7469.

Rilling JK, Barks SK, Parr LA, Preuss TM, Faber TL, Pagnoni G, et al. (2007): A comparison of resting-state brain activity in humans and chimpanzees. Proc Natl Acad Sci USA 104: 17146-17151. 
-Sakai E, Suemizu H, Shimada A, Hanazawa K, Oiwa R, Kamioka M, Tomioka I, Sotomaru Y, Hirakawa R, Eto T, Shiozawa S, Maeda T, Ito M, Ito R, Kito C, Yagihashi C, Kawai K, Miyoshi H, Tanioka Y, Tamaoki N, Habu S, Okano H, Nomura T (2009): Generation of transgenic non-human primates with germline transmission. Nature 459:523-527.

-Sakura H, Mori I (2013): Behavioral plasticity, learning, and memory in C. elegans. Curr Opin Neurobiol 23:92-99.

-Savage VM, Allen AP, Brown JH, Gillooly JF, Herman AB, Woodruff WH, West GB (2007): Scaling of number, size, and metabolic rate of cells with body size in mammals. Proc Natl Acad Sci USA 104:4718-4723.

Schmidt-Nielsen K (1984): Why Is Animal Size So Important? Cambridge, Cambridge University Press.

-Serrano-Saiz E, Poole RJ, Felton T, Zhang F, de la Cruz ED, Hobert O (2013): Modular control of glutamatergic neuronal identity in C. elegans by distinct homeodomain proteins. Cell 155:659-673.

-Shanahan M, Bingman VP, Shimizu T, Wild M, Güntürkün (2013): Large-scale network organization in the avian forebrain: a connectivity matrix and theoretical analysis. Front Comput Neurosci 7:89.

- Sherwood CC, Bauernfeind AL, Bianchi S, Raghanti MA, Hof PR (2012): Human brain evolution writ large and small. Prog Brain Res 195:237-254.
Shomrat T, Graindorge N, Bellanger C, Fiorito G, Loewenstein Y, Hochner B (2011): Alternative sites of synaptic plasticity in two homologous 'fan-out fan-in' learning and memory networks. Curr Biol 21:1773-1782.

-Somel M, Franz H, Yan Z, Lorenc A, Guo S, Giger T, Kelso J, Nickel B, Dannemann M, Bahn S, Webster MJ, Weickert CS, Lachmann M, Pääbo S, Khaitovich P (2009): Transcriptional neoteny in the human brain. Proc Natl Acad Sci USA 106:5743-5748.

Stark CE, Squire LR (2001): When zero is not zero: the problem of ambiguous baseline conditions in fMRI. Proc Natl Acad Sci USA 98: 12760-12766.

-Strausfeld NJ, Hirth F (2013a): Deep homology of arthropod central complex and vertebrate basal ganglia. Science 340:157-161.

-Strausfeld NJ, Hirth F (2013b): Homology versus convergence in resolving transphyletic correspondences of brain organization. Brain $\mathrm{Be}-$ hav Evol 82:215-219.

Striedter GF (2005): Principles of Brain Evolution. Sunderland, Sinauer.

Striedter GF (2013): Bird brains and tool use: beyond instrumental conditioning. Brain Behav Evol 82:55-67.

Striedter GF, Charvet CJ (2008): Developmental origins of species differences in telencephalon and tectum size: morphometric comparisons between a parakeet (Melopsittacus undulatus) and a quail (Colinus virgianus). J Comp Neurol 507:1663-1675.
Striedter GF, Northcutt RG (1991): Biological hierarchies and the concept of homology. Brain Behav Evol 38:177-189.

van der Worp HB, Howells DW, Sena ES, Porritt MJ, Rewell S, O'Collins V, Macleod MR (2010): Can animal models of disease reliably inform human studies? PLoS Med 7:e1000245.

van der Woude E, Smid HM, Chittka L, Huigens ME (2013): Breaking Haller's rule: brain-body size isometry in a minute parasitic wasp. Brain Behav Evol 81:86-92.

Vopalensky P, Pergner J, Liegertova M, BenitoGutierrez E, Arendt D, Kozmik Z (2012): Molecular analysis of the amphioxus frontal eye unravels the evolutionary origin of the retina and pigment cells of the vertebrate eye. Proc Natl Acad Sci USA 109:15383-15388.

-Wey H-Y, Phillips KA, McKay DR, Laird AR, Kochunov P, Davis MD, Glahn DC, Blangero J, Duong TQ, Fox PT (2013): Multi-region hemispheric specialization differentiates human from nonhuman primate brain function. Brain Struct Funct, DOI: 10.1007/s00429013-0620-9.

-Workman AD, Charvet CJ, Clancy B, Darlington RB, Finlay BL (2013): Modeling transformations of neurodevelopmental sequences across mammalian species. J Neurosci 33: 7368-7383.

Yopak K, Lisney T, Collin SE, Montgomery J, Darlington RB, Finlay BL (2010): Brain scaling from sharks to primates: a highly conserved vertebrate pattern. Proc Natl Acad Sci USA 107:12946-12951. 